\title{
Nutritional Status and Associated Factors among 24 to 59 Months old Urban Slum Children of Dhaka City
}

\author{
Bhuiyan MR ${ }^{1}$, Ahmad $\mathrm{SA}^{2}$, Shahidullah $\mathrm{M}^{3}$, Bhuiyan $\mathrm{MR}^{4}$
}

\begin{abstract}
Introduction: Malnutrition is one of the leading causes of disease in children. Prevention of under nutrition is one of the priority efforts to reduce childhood mortality. About $20 \%$ of the population is forced to reside in urban slum due to rapid urbanization. Lack of basic human necessities in the urban slum, adversely affects the nutritional status resulting in poor growth and development of the slum children.
\end{abstract}

Objectives: To assess nutritional status and associated factors among 24 to 59 months old urban slum children of Dhaka city in Bangladesh.

Materials and Methods: This cross sectional study was conducted during the period of March 2009 to June 2009 among 24 to 59 months old children of Vashantek slum of Dhaka. A total of 207 children who were available along with their mother during data collection period, were included as the study participants. For data collection face to face interview of the mother was performed and to determine the nutritional status of children anthropometric measurement was carried out.

Results: Among the total 207 children, $54.1 \%$ were male and $45.9 \%$ were female. The mean age \pm standard deviation of the children was $43.6 \pm 11.0$ months. As per Z-score of National Centre for Health Statistics (NCHS) reference classification, $45.4 \%$ children were underweight, $48.3 \%$ were stunted and $28.1 \%$ were wasted. Majority of the malnourished children were within 46 months of age. There was a little difference in nutritional status between male and female children. As per immunization schedule, $85.0 \%$ of the children completed their immunization. A higher proportion of the underweight children $(57.7 \%)$ were not exclusively breastfed in comparison to that of the wasted children (42.3\%). Moreover, it was revealed that there was a positive association between incomplete immunization and underweight, stunting and wasting $(p<0.05)$. The study also showed that there was an association between history of absence of exclusive breast feeding and underweight $(p<0.005)$ and wasting $(p<0.001)$ status of the children.

Conclusion: The study revealed that none of the slum children had normal nutrition, all of them were suffering from malnutrition and majority of them had stunted growth or were underweight. As the slum children are a part of urban society and will be the future generation, it is expected that the finding of this study will sensitize the policy makers to formulate policy and undertake measures to prevent malnutrition amongst the slum children.

Key-words: Nutritional status; Urban slums; Underweight; Stunting; Wasting.

\section{Introduction}

Malnutrition is one of the leading causes of disease in children. Globally, under nutrition is an underlying or associated cause of at least half of all childhood deaths ${ }^{1}$. Prevention of under nutrition in children is one of the top priority efforts to reduce childhood mortality. The effects of malnutrition on children are not limited to physical health, but extend to mental, social and spiritual well being and could be transmitted from one generation to another, constituting a vicious spiral ${ }^{2}$. A significant number of under five children are the victims of mortality and

1. Lt Col Mahbubur Rahman Bhuiyan, MBBS, MPH(HM), MBA(HCM), MPhil(PSM) Course, NIPSOM, Dhaka;

2. Professor Sk. Akhtar Ahmad, MBBS, DPH, MPH, Department of Occupational and Environmental Health, Bangladesh University of Health Sciences, Dhaka; 3. Col (Retd) Md Shahidullah, MBBS, DPH, M Phil(PSM), Ex Course chairman (PHA \& HM), AFMI, Dhaka Cant; 4. Dr. Mahfuzur Rahman Bhuiyan, MBBS, MPH (Melbourne), National Consultant, Chronic Disease Surveillance, WHO, Dhaka, Bangladesh. 
morbidity due to the curse of poverty, ignorance, religious social custom and prejudices. The malnutrition hampers the growth and development of a child when it is in mother's womb. Homelessness and poverty are international crises. Slums are heavily populated urban areas characterized by poverty and substandard housing where prevalence and the pervasiveness of poverty worldwide. Bangladesh is one of the poor countries in the world; with an estimated 3.4 million people are living in 5000 slums of its capital city, Dhaka ${ }^{3}$.

Rapid urbanization causes $20 \%$ of population to reside in urban slums. Non-availability of the basic human necessities in the urban slums adversely affects the growth and nutritional status of the children of slum dwellers. The exclusive breastfeeding, immunization status, birth order etc are directly related to nutritional status of children. Children of 24 to 59 months age group remain in very crucial stage, because in this age group after the end of breast feeding the children need proper food for their growth and development as well as to prepare them to go to school. A very little number of studies were conducted to know the nutritional status of slum children aged between 24 to 59 months living in Dhaka city. Therefore, this study was conducted to assess the nutritional status of children residing in Vashantek slum.

\section{Materials and Methods}

This cross sectional study was conducted with a view to determine the nutritional status of children aged 24-59 months of Vashantek slum of Dhaka city. A total of 207 children who lived in four slums of Vashantek area along with their mother and who were available during data collection period, were included as the sample of this study. The children who were found to be ill or suffered from any illness in the previous three months were not included in this study. The study was conducted from March 2009 to June 2009. Data were collected with data collection instruments with the help of trained female research assistant. Mother of the sample child was interviewed face to face and the height and weight of the children were measured. Anthropometric measurements were analyzed according to Z-scores of weight for age, height for age and weight for height. This study considered the National Center for Health Statistics (NCHS) of USA standard for classification of malnutrition. Apart from the anthropometric measurements of the children, information on various factors such as family size, breast-feeding history, history of exclusive breast-feeding, immunization status, birth order and socioeconomic status of the children etc. that affect the nutritional status were also obtained. Before collection of the data, an explanation was made to the respondents about the purpose of the study and the questionnaire. After pre-testing, necessary changes and modifications were made and the questionnaire was finalized and used for data collection. The data was entered into the computer and analyzed with the help of SPSS windows program version 12.0 .

\section{Results}

The distribution of children by age shows that, the mean age of the children was 43.6 months with standard deviation \pm 11.0 months. Majority of the children (45.4\%) were from 48-59 months age group. It was also found that, $54.1 \%$ studied children were male and the male and female ratio was 1.18:1(Table-I).

Table-l: Socio-demographic characteristics of study children $(n=207)$.

\begin{tabular}{|c|c|c|c|}
\hline \multicolumn{2}{|c|}{ Variables } & Frequency & $(\%)$ \\
\hline \multirow{3}{*}{ 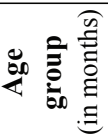 } & $24-35$ & 51 & 24.6 \\
\hline & $36-47$ & 62 & 30.0 \\
\hline & $48-59$ & 94 & 45.4 \\
\hline \multicolumn{2}{|c|}{$\begin{array}{l}\text { Mean }( \pm S D) \\
\text { age in months }\end{array}$} & \multicolumn{2}{|c|}{$43.6 \pm 11.0$} \\
\hline \multirow{2}{*}{ Sex } & Male & 112 & $(54.1)$ \\
\hline & Female & 95 & (45.9) \\
\hline
\end{tabular}

Figure-1 shows that, out of 207 study children of Vashantek slum 94(45.4\%) were underweight, $100(48.3 \%)$ were stunted and $58(28.1 \%)$ children were wasted.

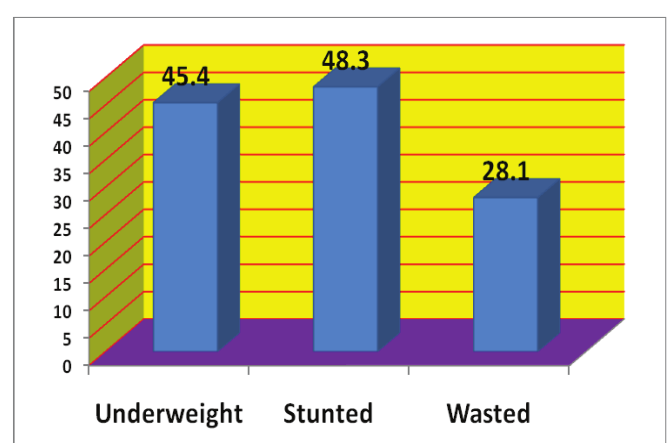

Fig-1: Distribution of children by weight for age, height for age and weight for height as Z-score. 
Majority i.e. $104(50.2 \%)$ of children's mother were educated up to primary level and $85(41.1 \%)$ were illiterate. On the other hand, paternal education status was found to be almost same, that is, $34.8 \%$ illiterate and $37.2 \%$ were educated upto primary level (Table-II).

Table-II: Distribution of children by parental education ( $n=207)$.

\begin{tabular}{|l|c|c|c|c|}
\hline \multirow{2}{*}{ Education Level } & \multicolumn{2}{|c|}{ Maternal Education } & \multicolumn{2}{c|}{ Paternal Education } \\
\cline { 2 - 5 } & Frequency & $\%$ & Frequency & $\%$ \\
\hline Illiterate & 85 & 41.1 & 72 & 34.8 \\
\hline Primary & 104 & 50.2 & 77 & 37.2 \\
\hline Class VI - X & 13 & 6.3 & 35 & 16.9 \\
\hline SSC and above & 5 & 2.4 & 23 & 11.1 \\
\hline
\end{tabular}

Table-III shows that $98.1 \%$ of respondent's family income was less than 10,000/= BDT per month.

Table-III: Distribution of children by monthly family income $(n=207)$.

\begin{tabular}{|l|c|c|}
\hline Income in BDT & Frequency & \% \\
\hline Up to $5,000 /=$ & 84 & 40.6 \\
\hline 5001 to $10,000 /=$ & 119 & 57.5 \\
\hline Above $10,000 /=$ & 4 & 1.9 \\
\hline
\end{tabular}

Table-IV shows that, out of 207 study children majority (94) were from '48-59' months age group. According to the age group, majority $(51.6 \%)$ of the underweight children belonged to ' $36-47$ ' months age group $(p<0.5)$. Again, among the stunted children majority $(59.7 \%)$ belonged to ' $36-47$ ' months age group $(p<0.05)$. Moreover, among the wasted children majority (47.1\%) belonged to '25-35' months age group $(p<0.005)$.

Table-IV: Distribution of malnourished children by age group $(n=207)$.

\begin{tabular}{|c|c|c|c|c|c|}
\hline \multirow{2}{*}{ Malnutrition } & \multicolumn{3}{|c|}{ Range of age (months) } & \multirow{4}{*}{} & \multirow{2}{*}{ Total } \\
\cline { 2 - 4 } & $\begin{array}{c}24-35 \\
(\mathrm{n}=51)\end{array}$ & $\begin{array}{c}36-47 \\
(\mathrm{n}=62)\end{array}$ & $\begin{array}{c}48-59 \\
(\mathrm{n}=94)\end{array}$ & & \\
\hline Underweight & $26(51.0)$ & $32(51.6)$ & $36(38.3)$ & $94(45.4)$ & $\mathrm{P}<0.5$ \\
\hline Stunting & $17(33.3)$ & $37(59.7)$ & $46(48.9)$ & $100(48.3)$ & $\mathrm{P}<0.05$ \\
\hline Wasting & $24(47.1)$ & $18(29.0)$ & $16(17.0)$ & $58(28.1)$ & $\mathrm{P}<0.005$ \\
\hline
\end{tabular}

${ }^{*}$ Results are in $\mathrm{n}(\%),{ }^{* *}$ Mutually exclusive, ${ }^{* * *}$ Chi-square value for underweight is $x 2=3.519$, for stunting $x 2=7.804$ and for wasting $\mathrm{x} 2=14.836$.

Among the total studied children, 129 (62.3\%) were exclusively breastfed. While comparing with not exclusively breastfed children, majority of non breastfed children were found to suffer more from underweight $(57.7 \%)$, stunted growth $(53.8 \%)$ and wasting $(42.3 \%)$. The difference of underweight $(p<0.05)$ and wasting $(p<0.005)$ between breastfed and non breastfed children was statistically significant (Table-V).
Table-V: Distribution of malnourished children by exclusive breast-feeding $(n=207)$.

\begin{tabular}{|l|c|c|c|c|}
\hline \multirow{2}{*}{ Malnutrition } & \multicolumn{2}{|c|}{ Exclusive breast-feeding } & \multirow{2}{*}{ Total } & \multirow{2}{*}{ p value } \\
\cline { 2 - 3 } & $\begin{array}{c}\text { Yes } \\
(\mathrm{n}=129)\end{array}$ & $\begin{array}{c}\text { No } \\
(\mathrm{n}=78)\end{array}$ & & \\
\hline Underweight & $49(38.0)$ & $45(57.7)$ & $94(45.4)$ & $\mathrm{P}<0.05$ \\
\hline Stunting & $58(45.0)$ & $42(53.8)$ & $100(48.3)$ & $\mathrm{p}<0.5$ \\
\hline Wasting & $25(19.4)$ & $33(42.3)$ & $58(28.1)$ & $\mathrm{p}<0.005$ \\
\hline
\end{tabular}

${ }^{*}$ Results are in $\mathrm{n}(\%),{ }^{* *}$ Mutually exclusive, ${ }^{* * *}$ Chi-square value for underweight $\times 2=7.616$, for stunting $\times 2=1.537$ and for wasting $\times 2=12.670$.

According to immunization status, out of 207 study children, 176 (85.0\%) were completely immunized and $31(15.0 \%)$ were not or incompletely immunized. Among the incompletely immunized children, majority $(64.5 \%)$ were underweight and stunted $(p<0.05)($ Table-VI).

Table-VI: Distribution of malnourished children by immunization status $(n=207)$.

\begin{tabular}{|c|c|c|c|c|}
\hline \multirow{2}{*}{ Malnutrition } & \multicolumn{2}{|c|}{ Immunization status } & \multirow{2}{*}{} \\
\cline { 2 - 3 } & $\begin{array}{c}\text { Complete } \\
\text { immunization }\end{array}$ & $\begin{array}{c}\text { Incomplete } \\
\text { immunization }\end{array}$ & \multirow{2}{*}{ Total } & p value \\
\cline { 2 - 3 } & $(\mathrm{n}=176)$ & $(\mathrm{n}=31)$ & & \\
\hline Underweight & $74(42.0)$ & $20(64.5)$ & $94(45.4)$ & $\mathrm{p}<0.05$ \\
\hline Stunting & $80(45.5)$ & $2064.5)$ & $100(48.3)$ & $\mathrm{p}<0.05$ \\
\hline Wasting & $43(24.4)$ & $15(48.4)$ & $58(28.1)$ & $\mathrm{p}<0.05$ \\
\hline
\end{tabular}

value for underweight $\times 2=5.369$, for stunting $\times 2=3.835$ and for wasting $\times 2=7.500$.

\section{Discussion}

This study was conducted with a view to determine the nutritional status of children aged between 24 to 59 months of Vashantek slums, Dhaka city. A total of 207 children who lived in those slums along with their mother were studied. Apart from the anthropometric measurements of the children, information on various factors such history of exclusive breast-feeding and immunization status of the children that may affect the nutritional status were also obtained. The mean age of the children was 43.6 months with standard deviation of \pm 11.0 months. Among them, maximum (45.4\%) children were in 48-59 months age group. Almost all the families $(98.1 \%)$ had monthly income below Taka $10,000 /-$. Both the mother and father of most of the children were illiterate or had education upto primary level. The findings of the present study have similarity with the findings of the studies conducted by Halder ${ }^{4}$ and Yazdani ${ }^{5}$. According to Z-scores, 
present study showed that majority of the slum children had underweight $(45.4 \%)$ or stunted growth $(48.3 \%)$ and a lesser proportion had wasting $(28.1 \%)$. The study of Yazdani ${ }^{5}$ found a better nutritional status of children in terms of underweight $(31.5 \%)$, stunted $(13.0 \%)$ and wasted $(18.5 \%)$ compared to that of the slum children of present study. This difference in the nutritional status might be due to the better living standard of children of Yazdani's study as they were from the family of Armed Forces Personnel. A study conducted by Arifeen $^{3}$ among under five children of slum and non-slum dwellers found almost similar poor nutritional status in terms of stunted growth (56\%) among slum children. According to Child Nutrition Survey $(2005)^{6}$, it was found that the proportion of underweight $(40 \%)$ and stunted growth $(46 \%)$ were higher compared to that of wasted children (15\%). The Bangladesh Demographic Health Survey $(2007)^{7}$ report also revealed a similar findings of underweight $(41 \%)$ and stunted growth $(43 \%)$ in children. The study conducted in 2004 by Karim ${ }^{8}$ on Nutritional Status of Young Children in Bangladesh found that $49 \%$ of the children were underweight, $43 \%$ of the children were stunted and $20 \%$ of them were wasted. All these findings of studies/reports including the findings of the present study revealed that there was a higher proportion of underweight and stunted growth amongst the children, while the proportion of wasting was less than half of them. On the other hand, Nutritional Surveillance Project $(2001)^{9}$ which was conducted almost 10 years back found that nationally, around $60 \%$ of young children were underweight and 55\% were stunted. These findings revealed a poor nutritional status of children 10 years back compared to that of present study and national survey of recent past, which might be an indication that the food and nutritional intake of the children of Bangladesh has improved.

According to age of the children, it was found that underweight $(51.6 \%)$ and stunted $(59.7 \%)$ children were significantly $(p<0.05)$ more in the age group of 36 to 49 months, while wasted children were more in the age group of 24-35 months. Child Nutrition Survey $(2005)^{6}$ also found that underweight $(51.6 \%)$ and stunted $(59.7 \%)$ children were significantly $(p<0.05)$ more in the age group of $36-47$ months. Study conducted by Karim ${ }^{8}$ found that occurrence of malnutrition was consistent with the children's age. As the children's age increased, the prevalence of the stunting continued up to about two years of life and the prevalence of underweight and wasting continued increased up to about three years of life. Then the rate declined and continued declining up to the fifth year of life. The present study also revealed that the children within the age of 46 months suffered more from malnutrition.

Exclusive breast-feeding is the most important determinant of child nutritional status as well as disease free life of a child. Due to mass awareness about merits of exclusive breast feeding the rate is increasing day by day. In the present study it was found that, among 207 study children, about two third $(62.3 \%)$ were exclusively breastfed and one third $(37.7 \%)$ were not exclusively breastfed for initial 6 months. According to Yazdani ${ }^{5}$ and Child Nutrition Survey $(2005)^{6}$ report $64 \%$ and $58 \%$ children were exclusively breastfed respectively. The findings of present study are found to be consistent with these findings in breastfed children. Further, it was found in the present study that amongst the not exclusively breastfed children incidence of underweight $(57.7 \%)$ and stunted growth $(53.8 \%)$ were significantly $(p<0.005)$ higher when compared to that of wasted $(42.3 \%)$ incidence of children. The study of Yazdani ${ }^{5}$ also found that, among the not exclusively breastfed children, the underweight, stunted and wasted children were $55.6 \%, 61.5 \%$ and $45.9 \%$ respectively. Similarly, according to Child Nutrition Survey $(2005)^{6}$ the incidence of underweight and stunting among the not exclusively breastfed children were greater than exclusively breastfed children. A similar finding was also found in the study of Giashuddin ${ }^{10}$ conducted in Bangladesh which showed that exclusively breastfed children were nutritionally better than non-exclusive breastfed children $(p<0.001)$. However, the nutritional statuses of the children of present study in terms of underweight, stunting and wasting were more prevalent among non-exclusively breastfed children when compared to that of children of exclusively breastfed. Therefore, the present study revealed the relationship between prevalence of malnutrition and non-exclusive breastfeeding. These findings conform to the findings of the study conducted by Rao ${ }^{11}$ in India, where it was revealed that shorter period of exclusive breast feeding resulted in under nutrition. Therefore, from the present study finding it can be reasonably conferred that exclusive breast-feeding has a great role in preventing malnutrition among the 
children. Regarding immunization status, it was found in this study that among the slum children $85 \%$ were completely immunized. Studies conducted by Rashid ${ }^{12}$, Yasmeen $^{13}$ and BDHS $(2007)^{7}$ found that among the study population, $56 \%, 47 \%$ and $82 \%$ children were completely immunized respectively. Amongst the non-immunized children, prevalence of underweight $(64.5 \%)$ and stunted $(64.5 \%)$ were found to be more when compared to that of wasted children (48.4\%). Immunization against seven communicable diseases according to the schedule of EPI programme has drastically reduced the child morbidity and mortality during last two decades. According to Statistical Pocket Book of Bangladesh $(2007)^{14}$ the prevalence of underweight among the non-immunized children was $60.8 \%$ which was almost similar to the present study finding. Study conducted by Dwivedi ${ }^{15}$ in slum of Bhopal, India, found that non-immunized children experienced more malnutrition $(66.4 \%)$. In the study of Zondag $^{16}$ held in rural Zambia, it was found that incomplete immunization was related to highest number of malnutrition related problems among the under five children. Therefore, all these studies include the present study have similarity in findings of incomplete immunization and occurrence of malnutrition.

\section{Conclusion}

The children are the future builders of a nation. The nation's productivity and development completely depend on proper growth and development of the children population. A healthy child is an asset for a nation. In this study, it was found that all the slum children were suffering from malnutrition in terms of underweight, stunted growth and wasting. Amongst them, underweight and stunted growths were found to be more particularly in the higher age group of children. Incomplete immunization status and history of non-exclusive breast feeding were found to be associated with the higher occurrence of malnutrition. To build a healthy and prosperous nation, the future generation of this country should be protected from ill health and malnutrition. Children of the slum are contributing a greater number to the national statistics and are the future generation of the country; so, they should not be neglected. Policy should be formulated and measures should be undertaken to prevent malnutrition amongst them, so that they can grow up with a sound health.

\section{References}

1. De Onis M, Blossner M, Borghi E, Frongillo EA, Morris R. Estimates of global prevalence of childhood underweight in 1990 and 2015. JAMA 2004; 291:2600-6.

2. State of the Art series. United Nations Administrative Committee on Coordination- Subcommittee on Nutrition (ACC/SCN): Geneva; 1993.

3. Arifeen SE and Akter T. Infant Feeding and Child Nutritional Status 2006, Bangladesh Urban Health Survey, 2008: 399-419.

4.Halder B. A study on Nutritional Status of Under five Children of Class III and Class IV Employees of Army in Dhaka cantonment (Thesis). Dhaka: IPGM\&R; 2000: 38-55.

5. Yazdani MS. Nutritional status and associated factors of two to five years children of Armed Forces personnel living the parents in Dhaka cantonment(Thesis), Dhaka, 2007.

6. Child and Mother Nutritional Survey of Bangladesh. Bangladesh Bureau of Statistics, Planning Division, Ministry of Planning, Government of the People's Republic of Bangladesh. 2005.

7. Bangladesh Demographic and Health Survey 2007. National Institute of Population Research and Training (NIPORT) Dhaka, 2009; 131-59.

8. Karim R, Khan $\mathrm{NI}$ and Akharuzzaman M. Nutritional Status of Young Children in Bangladesh National Program Area; A case study. The Bangladesh Development Studies, 2004; Vol. XXX (1\&2): 129-36.

9. HKI/IPHN. Evaluating national nutrition programs in Bangladesh: the role of the Nutritional Surveillance Project, Nutritional Surveillance Project Bulletin No-5, June,2001; 1.

10. Giashuddin MS, Kabir M, Rahman A, Hannan MA. Exclusive breastfeeding and nutritional status in Bangladesh. Indian Journal of Pediatrics 2003; 70(6): 471-5.

11. Rao S, Joshi SB, Kelkar RS. Changes in nutritional status and morbidity over time among pre-school children from slum in Pune, India. Indian Pediatrics. 2000; 37(10):1060-71.

12. Rashid KM, Rahman M, Hyder S. Rashid, Khabir. Hyder's Textbook of Community Medicine and Public Health. 4th ed. Dhaka: RHM Publisher; 2007; 126, 413.

13. Yasmeen S. Nutritional Status of Under five Children attending the outpatient department of paediatrics in Bangladesh Medical college (Thesis). Dhaka: IPG\&R; 1996: 38-41.

14. Statistical pocket book of Bangladesh, Bangladesh Bureau of Statistics, Planning division, Ministry of Planning, Government of the Peoples Republic of Bangladesh 2007; $3,375,388,405-10$.

15. Dwivedi SN, Banerjee N, Yadav OP. Malnutrition among children in an urban Indian slum and its associations. Indian J Matern Child Health. 1992; 3(3):79-81.

16. Zondag AM, Nouwen JL, Voorhoeve HW. Immunizations and nutritional status of under fives in rural Zambia. The Central African Journal of Medicine, 1992; 38(2): 62-6. 